\title{
Identificação do perfil de usuários de um Restaurante Popular do Município de Campinas
}

\author{
Renata Cristina Gobato ${ }^{1}$, Giseli Panigassi ${ }^{2}$, Juliana Pasti Villalba ${ }^{3}$
}

Os restaurantes populares são unidades de alimentação e nutrição destinadas ao preparo e comercialização de refeições saudáveis, ofertadas a preços acessíveis à população, que devem localizar-se preferencialmente em grandes centros urbanos. Tais restaurantes devem proporcionar a complementação alimentar dos grupos mais vulneráveis que, por falta de tempo ou recursos, não conseguem ter acesso a uma refeição saudável pelo menos uma vez por dia. O objetivo da pesquisa foi conhecer o perfil de usuários de um restaurante popular do Município de Campinas e refletir sobre a contribuição do restaurante popular para a segurança alimentar e nutricional dos usuários. Trata-se de um estudo transversal, o qual entrevistou 129 usuários. A partir de um questionário estruturado com questões de múltipla escolha, delineou-se o perfil dos usuários. A coleta dos dados foi realizada nos meses de agosto e setembro de 2008. A média de idade dos usuários é de 47,7 anos, sendo que 41\% possuem trabalho remunerado; 15,5\% têm como única refeição o almoço adquirido no "Restaurante Bom Prato" e possuem em média renda familiar de 2,4 salários mínimos. Observou-se que 94,6\% dos entrevistados consomem carne, $88,4 \%$ consomem frutas e $90,3 \%$ verduras e/ou legumes no restaurante Bom Prato, enquanto que no jantar em casa apenas 58,9\% consomem carne, $28,7 \%$ frutas e $41,5 \%$ verduras e/ou legumes. Concluiu-se que o "Restaurante Bom Prato" é importante para a segurança alimentar e nutricional de seus usuários, pois proporcionou à amostra, uma maior variedade de grupos de alimentos no almoço comparada ao jantar em casa e também comparada ao tipo de refeição realizada pelos pesquisados antes de sua inauguração.

Palavras-chave: restaurante Bom Prato, restaurantes populares, segurança alimentar e nutricional.

\section{Identifying the users' profile of a "Restaurante Popular" in the city of Campinas}

Restaurantes Populares are food and nutrition units for the preparation and sale of healthy meals, offered at affordable prices to the population, which should preferably be located in large urban areas. These restaurants must provide complementary nutrients to vulnerable groups which, due to lack of time or means, do not have access to at least one healthy meal a day. The aim of this study was to define the profile of users of the Restaurante Popular in the city of Campinas and reflect on its contribution for the food security and nutrition of the users. This is a cross-sectional study that interviewed 129 customers. The profile of the restaurant's customers was outlined from a structured questionnaire. The data was collected from August through September 2008. The average age of the customers was $47.7 ; 41 \%$ were employed; $15.5 \%$ had only one meal per day, secured at the Restaurante Popular, and the average income of the sample was 2.4 Minimum Wages. It was observed that 94.6\% of the customers consumed meat, $84.4 \%$ consumed fruits and $90.3 \%$ vegetables at the Restaurante Popular during lunch time, while at home, the intake of meat, fruits and vegetables declined to $58.9 \%, 28.7 \%$ and $41.5 \%$, respectively, at dinnertime. The Restaurante Popular was important to their customers' food security and nutrition

\footnotetext{
1 Nutricionista Pós-Graduada em Nutrição no Sistema Digestório pela Faculdade de Ciências Médicas, Universidade Estadual de Campinas (UNICAMP). Correspondência: Rua Samuel Fragoso de Coimbra, 457, CEP 13271-280, Valinhos, SP. E-mail: renatagobato@gmail.com

2 Profa. Universidade Paulista (UNIP). Dra. em Saúde Coletiva pela Faculdade de Ciências Médicas (FCM), Universidade Estadual de Campinas (UNICAMP).

3 Profa. Universidade Paulista (UNIP). Dra. em Saúde Coletiva pela Faculdade de Ciências Médicas (FCM), Universidade Estadual de Campinas (UNICAMP).
} 
as it contributed with a more nutritious meal for a vulnerable group of the population that frequently eat at the Restaurante Popular.

Key-words: Bom Prato restaurant, restaurantes populares, food security and nutrition.

\section{INTRODUÇÃO}

No Brasil, até meados da década de 1940, existia uma concepção de que a fome era um fenômeno natural, ou seja, sua origem estava pautada em causas naturais, em acidentes climáticos. Esta concepção naturalista nem sempre vigorou em sua plenitude e começou a perder legitimidade com o processo de urbanização e industrialização do país. Tal fato se deu pela grande dimensão que o flagelo social, pobreza, fome e desnutrição, tomou no país - o que propiciou a entrada da classe trabalhadora no cenário político brasileiro, reivindicando por melhores condições de vida - e pela contribuição de estudiosos sobre o fenômeno da fome, que por meio de pesquisas conseguiram mostrar este fenômeno como produto da desigualdade socioeconômica [1,2,3,4].

A partir daí foram implementadas várias políticas na tentativa de reduzir a fome e riscos de desnutrição das populações carentes, mas até a década de 1990 essas políticas caracterizaram-se por serem verticais e centralizadas, por terem uma forte perspectiva desenvolvimentista e por associarem o flagelo social, fome e desnutrição, ao subdesenvolvimento $[5,6,7]$.

Dalt \& Gouvêa ${ }^{[8]}$ ao fazerem uma análise da literatura existente, citam os seguintes aspectos inovadores das políticas implementadas a partir da década de 1990 em diante: descentralização, solidariedade, parcerias, formas de ação e controle, distanciamento do clientelismo, mapa da fome como estratégia para atingir os municípios mais pobres e concluem que os impactos positivos verificados foram a melhoria no perfil nutricional, o desempenho escolar das crianças e a ampliação do acesso a outros benefícios.

Uma dessas estratégias de intervenção para a Segurança Alimentar, na década de 1990, foi à criação dos Restaurantes Populares. Esta iniciativa vem se difundindo pelo país desde meados dos anos 1990, a partir das experiências conduzidas pela prefeitura de Belo Horizonte. Alguns registros mostram que essa modalidade de assistência à população carente já existe no Brasil desde a década de 1910 e que eram administrados pelo poder público. Em Belo Horizonte (MG) esses restaurantes foram reintroduzidos na década de 1950 e tinham como objetivo alimentar operários, estudantes e o público trabalhador do centro da cidade. O Restaurante Popular foi um dos vários instrumentos de intervenção da Política de Abastecimento e Segurança Alimentar do Município de Belo Horizonte, que já foi reconhecida nacional e internacionalmente como uma prática inovadora, eficiente e bem sucedida de administração pública. Tornou-se uma referência no fornecimento de alimentação a baixos preços, garantindo aos trabalhadores de baixa renda e à população que transita no Centro, alimentação de qualidade a preço acessível. A implantação dos Restaurantes Populares foi se difundindo em outros estados, como no Rio de Janeiro e em São Paulo [9,10].

No ano 2000, foi criado pelo Governo do Estado de São Paulo e desenvolvido pela Secretaria de Agricultura e Abastecimento, o Programa "Restaurantes Populares" intitulado Bom Prato. Este projeto de cunho social visa oferecer segurança alimentar a população de baixa renda, fornecendo em sua rede de restaurantes populares, refeições balanceadas com qualidade, através de um cardápio variado. As refeições totalizam 1600 calorias e são compostas de arroz, feijão, carne, farinha de mandioca, salada, acompanhamento, suco, sobremesas e pão. O custo de cada refeição é R\$3,25. O Governo do Estado subsidia R \$2,25, conforme Resolução SAA 22, de 01.08.2005, fazendo com que o usuário tenha uma refeição completa pagando apenas $\mathrm{R} \$ 1,00$. Menores de seis anos de idade não pagam e o Estado assume o custo integral da refeição. Através de seu gerenciamento, pela Coordenadoria de Desenvolvimento dos Agronegócios (CODEAGRO), esse programa conta atualmente, com 30 unidades em operação - abrangendo desde a capital paulista, até as cidades do interior, tais como: Campinas, São José dos Campos, São José do Rio Preto, entre outras [9].

Atualmente, o Programa Restaurante Popular é um dos programas integrados à rede de ações e programas do Fome Zero, atual política de inclusão social do Brasil. Tem como objetivo apoiar a implantação e a modernização de restaurantes públicos 
populares geridos pelo setor público municipal/ estadual, visando à ampliação de oferta de refeições prontas saudáveis, nutricionalmente balanceadas e a preços acessíveis, ao custo de $\mathrm{R} \$ 1,00$, servidas em locais apropriados e confortáveis de forma a reduzir o número de pessoas em situação de insegurança alimentar ${ }^{[1]}$.

Por questões de restrição orçamentária, muitas pessoas não têm acesso ao mercado tradicional de refeições prontas. Muitos dos trabalhadores que recebem o benefício do auxilio refeição preferem utilizá-lo na compra de alimentos in natura em estabelecimentos tais como supermercados, açougues e padarias. $\mathrm{Na}$ maioria das vezes, esses trabalhadores residem em áreas distantes dos seus locais de trabalho, e, desta forma, o custo e o tempo necessário ao deslocamento os impedem de fazer as refeições em casa, tendo como solução o almoço por meio de marmitas. Essa situação tem-se transformado em uma violação diária dos hábitos alimentares, comprometendo a qualidade das refeições e aumentando o risco de agravos à saúde. Portanto, os restaurantes populares devem estar localizados em regiões de grande movimentação, como por exemplo áreas centrais da cidade, próximas a locais de transporte de massa e/ou em áreas de grande circulação de população de baixa renda. A instalação deve permitir que os usuários não tenham que utilizar meios de transporte para a realização de deslocamentos no horário de almoço [9,11].

Os restaurantes podem também atuar como reguladores de preços dos estabelecimentos localizados em seu entorno, contribuindo também para uma elevação da qualidade das refeições servidas e higiene dos estabelecimentos ${ }^{[11]}$.

Uma pesquisa realizada em 2005 para a identificação do universo de restaurantes populares existentes no Brasil mostrou cadastro de 111 restaurantes populares, sendo $94 \mathrm{em}$ funcionamento e 17 em implantação. Esses estão localizados em 18 estados e 59 municípios, sendo que $50 \%$ deles concentram-se na região Sudeste, cabendo destacar também a presença expressiva no Estado do Rio Grande do Sul (12 unidades) e no Distrito Federal (9 unidades). Mais de $50 \%$ da implantação desses restaurantes ocorreram após 2003, com a implantação do Programa Fome Zero ${ }^{[12]}$.

Um artigo publicado por Costa (1947) [13] há cinquenta e três anos retrata, ainda, a importância dos restaurantes populares, bem como a necessidade da integração com outros projetos sociais de combate a fome e a desnutrição.

O restaurante popular é sempre um
organismo de manutenção e instalação
dispendiosa e o vulto econômico dos
investimentos não cria a possibilidade de
fundar, principalmente nos países de extensa
desnutrição popular, o número de
restaurantes que seria necessário manter para
atender as necessidades alimentares das
massas proletárias... Os restaurantes populares
possuem valor restrito: deles só se beneficiam
frações de uma coletividade, grupos mais ou
menos extensos de trabalhadores,
continuando entregue à insídia da fome
crônica um número muito maior de homens e
mulheres que têm na força do trabalho o
único capital disponível. Mas no terreno da
educação alimentar é que os restaurantes
populares desempenham todo o seu papel
realmente útil às condições alimentares do
povo. É que eles concorrem para que se
criem novos hábitos alimentares, ensinando a
boa alimentação pelo exemplo, na lição
prática da ração cientificamente balanceada e
agradavelmente preparada (Costa, 1947, p.
417).

O propósito do presente trabalho foi conhecer o perfil de usuários do restaurante popular do Município de Campinas. Além disso, pretende-se refletir sobre a contribuição do restaurante popular para a segurança alimentar e nutricional dos usuários.

\section{MATERIAL E MÉTODOS}

Trata-se de um estudo transversal, composto por usuários do restaurante Bom Prato que é o campo empírico desta investigação. Este está situado no município de Campinas, que é uma das vinte mais populosas cidades brasileiras e é pólo, na região, de um dos maiores parques industriais e tecnológicos do País. Município, que está situado no Estado de São Paulo, tem $887 \mathrm{~km}^{2}$ e, desse total, 53\% são ocupados por área urbana. Segundo o Censo 2000, possui 969.596 habitantes. Desses, 953.218 vivem em área urbana, ocupando o 6 o lugar no ranking dos municípios com maior número de favelas no Brasil [14]; segundo dados da Secretaria Municipal de Habitação, conta com 234 núcleos de favelas e ocupações [15]. 
O restaurante é de fácil acesso pela população de outros bairros e municípios da Região Metropolitana de Campinas por se encontrar na área central e próximo a terminais de ônibus. Em média, 1.800 usuários frequentam o Restaurante Bom Prato de Campinas diariamente. $\mathrm{O}$ restaurante, implantado em 2002, é administrado por entidade social e pelo governo do Estado de São Paulo. Campinas possui apenas essa unidade, que não supre a necessidade do município com aproximadamente um milhão de habitantes e que tem ao seu redor cidades que dependem da sua economia.

O tamanho da amostra probabilística representativa dessa população foi calculado no programa Epi Info, no Módulo Stat Calc. Os parâmetros usados para o cálculo foram frequência esperada de $6 \%$ de insegurança alimentar grave, desvio padrão de 4\% (2-10) e um nível de confiança de $95 \%$. O resultado mostrou a necessidade de uma amostra de 126 usuários para realização do estudo.

O instrumento utilizado para coleta de dados foi um questionário estruturado, contendo 21 questões de múltipla escolha sobre alimentação, inclusão em programas sociais e hábitos de vida, baseado no questionário aplicado na pesquisa realizada pelo IBOPE no ano de 2005 [16]. Também fez parte do instrumento, um conjunto de questões iniciais para caracterizarem o perfil demográfico, social e econômico dos participantes.

As entrevistas foram realizadas por um dos pesquisadores em oito dias alternados, excluídos os finais de semana, durante os meses de agosto e setembro de 2008. A amostragem foi aleatória simples com reposição. Usou-se uma tabela de números aleatórios para efetuar a seleção dos participantes na saída do restaurante.

Os critérios de exclusão utilizados foram os seguintes: idade inferior a 18 anos, pela necessidade de um responsável para autorizar e acompanhar a entrevista e não saber ler e escrever devido a necessidade de leitura e assinatura do Termo de Consentimento Livre e Esclarecido.

Todos os participantes foram esclarecidos sobre o propósito da pesquisa e assinaram o Termo de Consentimento Livre e Esclarecido. O estudo obteve aprovação do Comitê de Ética em Pesquisa, protocolo no 127/08 CEP/ICS/UNIP.
Os dados coletados foram transcritos para meio eletrônico para validação e análise. As variáveis selecionadas para análise foram: renda familiar em salários mínimos (conversão em setembro de 2008); idade em anos completos e categorizada em menor de 60 anos ou mais (idosos); tipo de transporte utilizado para frequentar o Restaurante (carro/moto, ônibus ou a pé); escolaridade categorizada em analfabeto, primeiro grau incompleto e primeiro grau completo ou mais; recebe algum benefício (Cesta Básica, Bolsa Família, Aposentadoria ou Pensão); tem trabalho remunerado (sim ou não); tem carteira assinada (sim ou não); possui residência fixa (sim ou não) e mora em Campinas (sim ou não).

Alimentos consumidos no restaurante e em casa, a partir de uma lista fechada com possibilidade de respostas sim ou não, foram usados para avaliar a segurança alimentar dos participantes, no componente qualidade da alimentação.

A referência utilizada para estabelecer a dieta esperada foi a pirâmide alimentar ${ }^{[17]}$. De acordo com a recomendação de porções ao dia, considerou-se que nas refeições principais avaliadas, almoço e jantar, os seguintes grupos deveriam estar presentes: cereais, leguminosas, carnes, verduras/legumes e, de acordo com as Estratégias Mundiais para Alimentação Saudável e Atividade Física [18], a qual recomenda 5 porções de frutas por dia, também inclui-se como parâmetro de avaliação uma fruta ou suco de fruta em cada refeição analisada.

Ao final, considerou-se ideal a refeição, em casa ou no restaurante, que incluísse os seguintes grupos: cereais, leguminosas, carnes, verduras/legumes e fruta ou suco de fruta.

Também foram usadas, como indicadores de segurança alimentar, as variáveis "realização das principais refeições diárias (café da manhã, almoço e jantar)", "motivo para fazer a refeição no restaurante avaliado (preço, sabor, qualidade, variedade e localização)", "preocupação com a qualidade dos alimentos que consome (sim ou não)" e "percepção do participante sobre a qualidade de sua alimentação (saudável e não saudável)".

Foram realizadas as frequências percentuais das variáveis e aplicados os testes exato de Fischer e qui-quadrado com valor de 5\%, para ambos, como limite de significância estatística da associação bivariada. 
No processamento e na análise dos dados utilizou-se o programa Epi Info e para a elaboração de tabelas e gráficos o programa Excel.

\section{RESULTADOS}

Os usuários do restaurante Bom Prato participantes da pesquisa tem em média 47,7 anos (Tabela 1), sendo que a maioria apresenta menos de 60 anos de idade (76\%), ressaltando que crianças e adolescentes foram excluídos da amostra; $53,4 \%$ são do sexo masculino (Tabela 2) e o número médio de componentes na família é de 3 pessoas, sendo que a média da renda familiar é de 2,4 salários mínimos (Tabela 1). A maior parte dos entrevistados possui residência fixa $(83,7 \%)$, residem em Campinas $(80,6 \%)$, $75,2 \%$ utilizam o ônibus como meio de transporte, $23,3 \%$ vão a pé e $1,5 \%$ utilizam carro para ir ao restaurante (Tabela 2).

Tabela 1. Distribuição média de idade, renda familiar e número de pessoas na família dos usuários do Restaurante Bom Prato. Campinas, 2008.

\begin{tabular}{lcc}
\hline \multicolumn{1}{c}{ Variável } & $n$ & Média \\
\hline Idade (anos) & 129 & 47,7 \\
Salário mínimo (Reais)* & 117 & 2,4 \\
№ de pessoas na família & 129 & 3,0 \\
\hline
\end{tabular}

* 12 participantes sem informação de renda.

Em relação à escolaridade $1,5 \%$ nunca frequentaram a escola, porém sabiam ler e escrever e $45,7 \%$ não completaram o ensino fundamental (Tabela 2).

Dos 129 entrevistados, 8,5\% estão estudando atualmente, sendo que desses $27,3 \%$ estão cursando o ensino fundamental, $27,3 \%$ o ensino médio e $45,5 \%$ estão na faculdade (Tabela 2).

O estudo também apontou que mais da metade dos entrevistados $(58,9 \%)$ não possuem trabalho remunerado e que dos $41,1 \%$ que possuem, $50,9 \%$ tem carteira assinada. Quanto aos benefícios dados pelo Governo, 19,4\% dos usuários responderam ter algum tipo de benefício como Bolsa Família (52\%), Aposentadoria (44\%) e INSS (4\%). As respostas também mostram que 16,3\% dos usuários recebem Cesta Básica (Tabela 2).

Considerando a preocupação com a alimentação, $89,1 \%$ preocupam-se em consumir alimentos saudáveis e 76,7\% acham que sua alimentação é saudável (Tabela 3). Comparando os tipos de alimentos que os usuários consomem no restaurante popular com os ingeridos no jantar, pode-se verificar que o restaurante popular proporciona uma alimentação mais completa e mais segura no componente variedade (Figura).

Tabela 2. Perfil dos usuários do restaurante Bom Prato do município de Campinas. Campinas, 2008.

\begin{tabular}{lrr}
\hline \multicolumn{1}{r}{ Perfil dos usuários } & $n$ & $\%$ \\
\hline Idade & & \\
$<60$ anos & 98 & 76,0 \\
$\geq 60$ anos & 31 & 24,0 \\
& & \\
Gênero & & \\
Masculino & 69 & 53,5 \\
Feminino & 60 & 46,5 \\
& & \\
Residência & & \\
Possuem residência fixa & 108 & 83,7 \\
Residem em Campinas & 104 & 80,6 \\
& & \\
Meio de transporte até o Restaurante Popular & \\
OOnibus & 97 & 75,2 \\
Carro & 2 & 1,5 \\
A pé & 30 & 23,3
\end{tabular}

Escolaridade

Não completaram o Ensino $\quad 59 \quad 45,7$

Estudam atualmente $\quad 11 \quad 8,5$

Cursam o Ensino Fundamental $\quad 3 \quad 27,3$

Cursam o Ensino Médio $\quad 3 \quad 27,3$

Cursam o Ensino Superior $\quad 5 \quad 45,5$

Trabalho

Possuem trabalho remunerado $\quad 53 \quad 41,0$

Possuem carteira assinada $\quad 27 \quad 50,9$

Benefícios dados pelo Governo

Recebem ajuda do Governo $\quad 25 \quad 19,4$

Recebem Bolsa Família $\quad 13 \quad 52,0$

Recebem Aposentadoria $\quad 11 \quad 44,0$

Recebem INSS 114,0

Recebem cesta básica $21 \quad 16,3$ 
Tabela 3. Perfil da alimentação dos usuários do restaurante Bom Prato do Município de Campinas. Campinas, 2008.

\begin{tabular}{lrc}
\hline \multicolumn{1}{c}{ Perfil da alimentação dos usuários } & $n$ & $\%$ \\
\hline Alimentação saudável & 115 & 89,1 \\
Preocupam-se em consumir alimentos saudáveis & 99 & 76,7 \\
Acham a própria alimentação saudável & & \\
& & \\
Frequência ao Restaurante Popular & 56 & 43,4 \\
Duas a três vezes por semana & 30 & 23,3 \\
Diariamente & & \\
O que consumia no almoço antes da implantação do Restaurante Popular & 25 & 19,4 \\
Prato feito ou marmitex comprado & 54 & 41,9 \\
Almoçava somente quando chegava em casa & 30 & 23,3 \\
Lanche rápido & 7 & 5,4 \\
Marmita preparada em casa & & \\
& & 15,5 \\
O almoço no restaurante é a única refeição diária & 20 & 84,5 \\
Sim & 109 & \\
Não & & 78,3 \\
A quantidade de alimentos ingerida no dia é suficiente & 101 & 21,7 \\
Sim & 28 & \\
Não & & \\
\hline
\end{tabular}

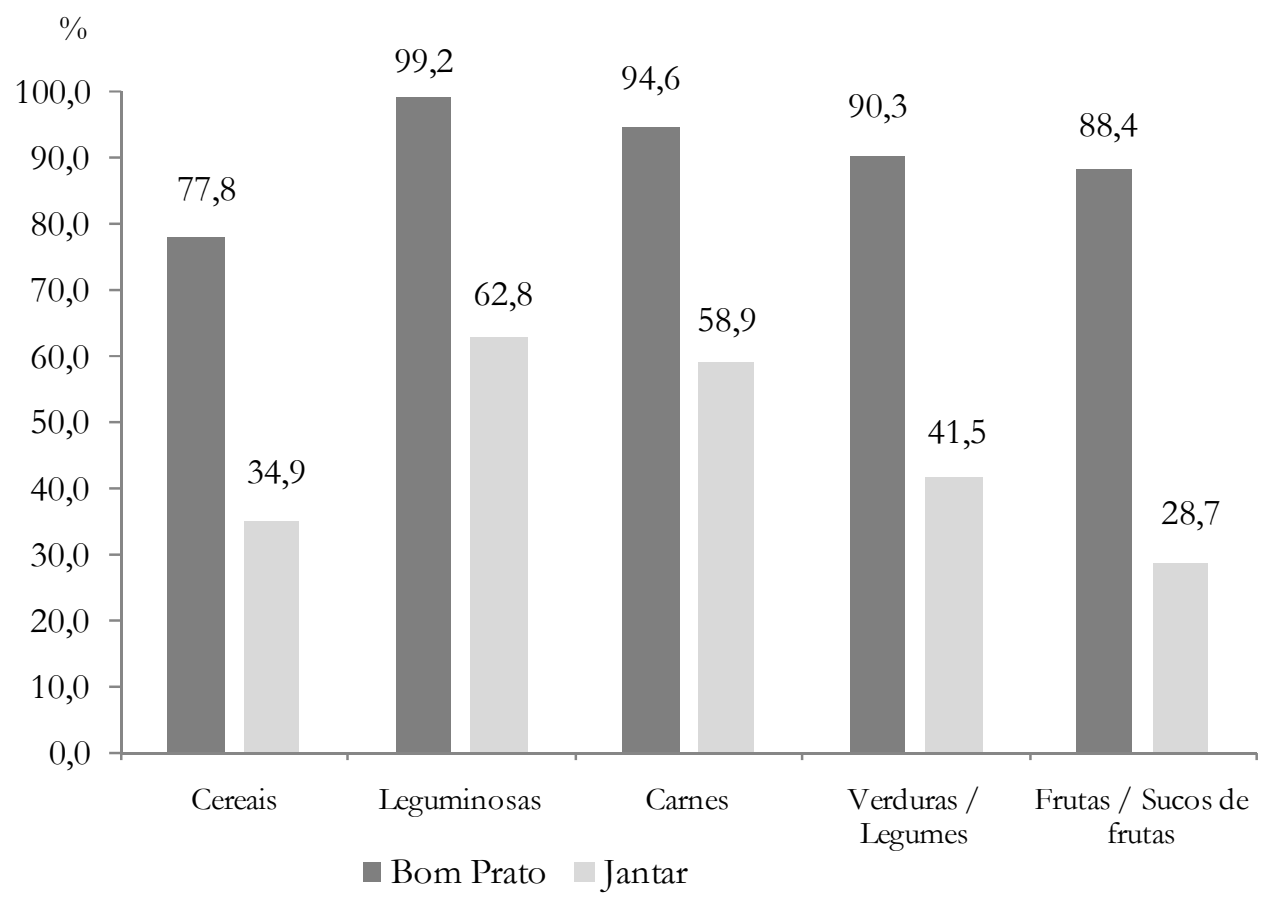

Figura. Comparação entre os alimentos consumidos no Restaurante Bom Prato e no jantar dos entrevistados. Campinas, 2008. 
A maioria dos entrevistados $(43,4 \%)$ frequenta o restaurante Bom Prato duas a três vezes na semana e 23,3\% frequentam diariamente. Antes da implantação do restaurante 19,4\% consumiam prato feito, 41,9\% almoçavam em casa, 23,3\% comiam lanche rápido e $5,4 \%$ levavam marmita de casa (Tabela 3).

Para $84,5 \%$, essa não é a única refeição do dia e realizam, além do almoço no restaurante, o jantar, mas $21,7 \%$ disseram que a quantidade ingerida de alimentos durante o dia inteiro não é suficiente (Tabela 3).

Segundo a pesquisa realizada (Tabela 4), a grande maioria da população estudada $(68,2 \%)$ leva em consideração o baixo preço da refeição, 43,4\% frequenta o local porque gostam da refeição fornecida e 17,8\% porque é próximo do local de trabalho.

Tabela 4. Motivo para almoçar no Restaurante Popular. Campinas, 2008.

\begin{tabular}{|c|c|c|}
\hline $\begin{array}{c}\text { Motivo para almoçar no } \\
\text { Restaurante } *\end{array}$ & $n$ & $\%$ \\
\hline Gosta da refeição & 56 & 43,4 \\
\hline Fácil acesso & 23 & 17,8 \\
\hline Barato & 88 & 68,2 \\
\hline Outros & 8 & 6,2 \\
\hline
\end{tabular}

* Cada entrevistado pode escolher um ou mais motivos para almoçar no restaurante.

$\mathrm{Na}$ tabela 5, verifica-se que quem possui renda maior ou igual a um salário mínimo, realiza mais o jantar do que quem recebe menos de um salário mínimo no mês $(p=0,0052)$. Também se avaliou que $92,8 \%$ dos homens realizam o jantar enquanto que apenas 78,3\% das mulheres fazem essa refeição $(\phi=$ $0,0184)$, e quem possui residência fixa, janta mais do que quem não possui $(\phi=0,0455)$.

A condição de consumir legumes no jantar esteve mais presente entre os entrevistados que recebem o Bolsa Família ou que possuem residência fixa $(p<0,05)$ (Tabela 6$)$. A falta de preocupação com a alimentação saudável é mais evidente $(\phi<0,05)$ entre as pessoas de baixa escolaridade, do gênero masculino e residentes fora do município de Campinas (Tabela 7).

\section{DISCUSSÃO}

A caracterização dos usuários dos restaurantes populares é de fundamental importância para que possam ser articuladas outras ações que compõem a atual política nacional. Maluf ao analisar os resultados da pesquisa realizada pelo Instituto Polis aponta que estão pouco ou quase nada articulados com outras ações que comporiam a atual política nacional e conclui que essa desarticulação se deve à insuficiente incorporação do enfoque da Segurança Alimentar e Nutricional nas políticas locais e à presença de projetos de entidades privadas desconectadas das políticas públicas [19].

Ao analisar o perfil dos usuários entrevistados pode-se perceber que os resultados foram semelhantes aos da pesquisa realizada pelo IBOPE no ano de 2005, a pedido do Ministério do Desenvolvimento Social e Combate à Fome, onde foram entrevistados 600 frequentadores dos restaurantes localizados em cinco capitais do Brasil [16]. É interessante notar que, apesar de algumas análises apontarem para a ausência de ações nos restaurantes, como a educação alimentar, tanto no restaurante estudado como nos estabelecimentos da pesquisa realizada pelo IBOPE, é evidente a preocupação das pessoas em consumirem alimentos saudáveis, onde os resultados das pesquisas demonstram que mais de $86 \%$ têm essa preocupação.

A instalação dos restaurantes populares deve permitir que os usuários não tenham que utilizar meios de transporte para a realização de deslocamentos no horário de almoço, mas verifica-se que apenas 17,8\% dos usuários entrevistados afirmam que almoçam no restaurante pelo fato do mesmo ser próximo do trabalho, identificando que boa parte dos usuários não trabalha próximo ao restaurante.

Comparando a porcentagem de pessoas que utilizam o ônibus como meio de transporte para chegar ao restaurante, observa-se um valor de $40 \%$ na pesquisa realizada pelo IBOPE e $75,2 \%$ no restaurante estudado, mostrando que provavelmente a maioria dos usuários não reside próximo ao restaurante Bom Prato.

Com relação à frequência com que os usuários utilizam o restaurante, no estudo realizado, 43,4\% dos usuários frequentam de 2 a 3 vezes por semana e 23,3\% diariamente, observando-se uma diferença dos resultados obtidos na pesquisa IBOPE, onde $45 \%$ dos usuários frequentam diariamente e, $16 \%$, de 2 a 3 vezes na semana.

$\mathrm{Na}$ pesquisa realizada em 2007 no Restaurante Popular Mesa do Povo, situado em Fortaleza (CE), foram selecionados 51 usuários aleatoriamente, os quais foram submetidos à aplicação do inquérito alimentar, 
recordatório 24 horas e hábitos alimentares. Após inquérito alimentar procurando explorar aspectos relacionados às mudanças de hábitos alimentares dos pesquisados ocorridos após a frequência do restaurante, averiguou-se que $80,3 \%$ dos usuários disseram estar consumindo verduras, $11,9 \%$ citaram frutas, $13,7 \%$ citaram carnes e $66,7 \%$ dos entrevistados relataram que sua alimentação foi alterada após começar a frequentar o Restaurante Popular Mesa do Povo, mostrando que a frequência ao restaurante pode contribuir para uma melhora dos hábitos alimentares da população que o utiliza [20].

Tabela 5. Comparação das variáveis estudadas nessa população e a realização ou não do jantar. Campinas, 2008.

\begin{tabular}{|c|c|c|c|c|c|}
\hline \multirow{2}{*}{ Variável } & \multicolumn{2}{|c|}{$\begin{array}{c}\text { Realizam } \\
\text { o jantar }\end{array}$} & \multicolumn{2}{|c|}{$\begin{array}{c}\text { Não realizam } \\
\text { o jantar }\end{array}$} & \multirow{2}{*}{$p$-valor } \\
\hline & $n$ & $\%$ & $n$ & $\%$ & \\
\hline Renda familiar $* * *<1 \mathrm{SM}$ & 23 & 74,2 & 8 & 25,8 & $0,0052 *$ \\
\hline Renda familiar $* * * \geq 1 \mathrm{SM}$ & 81 & 94,2 & 5 & 5,8 & \\
\hline Idade $<60$ anos & 83 & 86,5 & 13 & 13,5 & $0,5101 *$ \\
\hline Idade $\geq 60$ anos & 28 & 84,8 & 5 & 15,2 & \\
\hline Analfabeto ou primeiro grau incompleto & 52 & 85,2 & 9 & 14,8 & $0,8037 * *$ \\
\hline Primeiro grau completo ou mais & 59 & 86,8 & 9 & 13,2 & \\
\hline Gênero feminino & 47 & 78,3 & 13 & 21,7 & $0,0184 * *$ \\
\hline Gênero masculino & 64 & 92,8 & 5 & 7,2 & \\
\hline Recebe cesta Básica & 16 & 73,2 & 5 & 23,8 & $0,1406 *$ \\
\hline Não recebe cesta básica & 95 & 88,0 & 13 & 12,0 & \\
\hline Recebe Bolsa Família & 12 & 92,3 & 1 & 7,7 & $0,4291 *$ \\
\hline Não recebe Bolsa Família & 99 & 85,3 & 17 & 14,7 & \\
\hline Trabalha & 48 & 90,6 & 5 & 9,4 & $0,2160 * *$ \\
\hline Não trabalha & 63 & 82,9 & 13 & 17,1 & \\
\hline Possui residência fixa & 96 & 88,9 & 12 & 11,1 & $0,0455 *$ \\
\hline Não possui residência fixa & 15 & 71,4 & 6 & 28,6 & \\
\hline Mora em Campinas & 90 & 86,5 & 14 & 13,5 & $0,4774 *$ \\
\hline Mora em outra cidade & 21 & 84,0 & 4 & 16,0 & \\
\hline
\end{tabular}


Tabela 6. Comparação das características dos entrevistados que consomem ou não legumes no jantar.

Campinas, 2008.

\begin{tabular}{|c|c|c|c|c|c|}
\hline \multirow[t]{2}{*}{ Variável } & \multicolumn{2}{|c|}{$\begin{array}{l}\text { Consomem } \\
\text { legumes }\end{array}$} & \multicolumn{2}{|c|}{$\begin{array}{c}\text { Não } \\
\text { consomem } \\
\text { legumes }\end{array}$} & \multirow[t]{2}{*}{$p$-valor } \\
\hline & $n$ & $\%$ & $n$ & $\%$ & \\
\hline Renda familiar $* *<1 \mathrm{SM}$ & 9 & 29,0 & 22 & 70,9 & $0,1401 *$ \\
\hline Renda familiar $* * \geq 1 \mathrm{SM}$ & 38 & 44,2 & 48 & 55,8 & \\
\hline Idade $<60$ anos & 39 & 40,6 & 57 & 59,4 & $0,4583 *$ \\
\hline Idade $\geq 60$ anos & 11 & 33,3 & 22 & 66,7 & \\
\hline Analfabeto ou primeiro grau incompleto & 27 & 44,3 & 34 & 55,7 & $0,2244 *$ \\
\hline Primeiro grau completo ou mais & 23 & 33,8 & 45 & 66,2 & \\
\hline Gênero feminino & 21 & 35,0 & 39 & 65,0 & $0,4137 *$ \\
\hline Gênero masculino & 29 & 42,0 & 40 & 58,0 & \\
\hline Se preocupa com a alimentação & 45 & 39,1 & 70 & 60,9 & $0,8044 *$ \\
\hline Não se preocupa com a alimentação & 5 & 35,7 & 9 & 64,3 & \\
\hline Acha que tem uma alimentação saudável & 40 & 40,4 & 59 & 59,6 & $0,4862 *$ \\
\hline Acha que não tem uma alimentação saudável & 10 & 33,3 & 20 & 66,7 & \\
\hline Recebe cesta Básica & 8 & 38,1 & 13 & 61,9 & $0,9455 *$ \\
\hline Não recebe cesta básica & 42 & 38,9 & 66 & 61,1 & \\
\hline Recebe Bolsa Família & 10 & 76,9 & 3 & 23,1 & $0,0029 *$ \\
\hline Não recebe Bolsa Família & 40 & 34,5 & 76 & 65,5 & \\
\hline Trabalha & 19 & 35,8 & 34 & 64,2 & $0,5710 *$ \\
\hline Não trabalha & 31 & 40,8 & 45 & 59,2 & \\
\hline Possui residência fixa & 47 & 43,5 & 61 & 56,5 & $0,0119 *$ \\
\hline Não possui residência fixa & 3 & 14,3 & 18 & 85,7 & \\
\hline Mora em Campinas & 39 & 37,5 & 65 & 62,5 & $0,5492 *$ \\
\hline Mora em outra cidade & 11 & 44,0 & 14 & 56,0 & \\
\hline
\end{tabular}

* Teste Qui-quadrado.

** 12 participantes sem informação de renda. 
Tabela 7. Comparação dos entrevistados que possuem preocupação ou não em ter uma alimentação saudável. Campinas, 2008.

\begin{tabular}{|c|c|c|c|c|c|}
\hline \multirow[t]{2}{*}{ Variável } & \multicolumn{2}{|c|}{$\begin{array}{l}\text { Se preocupam } \\
\text { em ter uma } \\
\text { alimantação } \\
\text { saudável }\end{array}$} & \multicolumn{2}{|c|}{$\begin{array}{l}\text { Não se } \\
\text { preocupam } \\
\text { em ter uma } \\
\text { alimantação } \\
\text { saudável }\end{array}$} & \multirow[t]{2}{*}{$p$-valor } \\
\hline & $n$ & $\%$ & $n$ & $\%$ & \\
\hline Renda familiar $* * *<1 \mathrm{SM}$ & 26 & 83,9 & 5 & 16,1 & $0,1787 *$ \\
\hline Renda familiar $* * * \geq 1 \mathrm{SM}$ & 79 & 91,9 & 7 & 8,1 & \\
\hline Idade $<60$ anos & 85 & 88,5 & 11 & 11,5 & $0,4963 *$ \\
\hline Idade $\geq 60$ anos & 30 & 90,9 & 3 & 9,1 & \\
\hline Analfabeto ou primeiro grau incompleto & 50 & 82,0 & 11 & 18,0 & $0,0130 * *$ \\
\hline Primeiro grau completo ou mais & 65 & 95,6 & 3 & 4,4 & \\
\hline Gênero feminino & 58 & 96,6 & 2 & 3,4 & $0,0104 * *$ \\
\hline Gênero masculino & 57 & 82,6 & 12 & 17,4 & \\
\hline Recebe cesta Básica & 20 & 95,2 & 1 & 4,8 & $0,2933 *$ \\
\hline Não recebe cesta básica & 95 & 88,0 & 13 & 12,0 & \\
\hline Recebe Bolsa Família & 13 & 100,0 & 0 & 0,0 & $0,2075 *$ \\
\hline Não recebe Bolsa Família & 102 & 88,0 & 14 & 12,0 & \\
\hline Trabalha & 50 & 94,3 & 3 & 5,6 & $0,1134 * *$ \\
\hline Não trabalha & 65 & 85,5 & 11 & 14,5 & \\
\hline Possui residência fixa & 97 & 89,8 & 11 & 10,2 & $0,4065 *$ \\
\hline Não possui residência fixa & 18 & 85,7 & 3 & 14,3 & \\
\hline Mora em Campinas & 96 & 92,3 & 8 & 7,7 & $0,0296 *$ \\
\hline Mora em outra cidade & 19 & 76,0 & 6 & 24,0 & \\
\hline
\end{tabular}

* Teste Exato de Fischer.

** Teste Qui-quadrado.

*** 12 participantes sem informação de renda.

No estudo realizado, $94,6 \%$ dos usuários consomem carne, $88,4 \%$ consomem frutas e $90,3 \%$ verduras e/ou legumes no restaurante Bom Prato, enquanto que no jantar em casa, $58,9 \%$ consomem carne, $28,7 \%$ frutas e $41,5 \%$ verduras e/ou legumes, mostrando que na ausência do restaurante, a população que o utiliza não realizaria uma refeição adequada como a oferecida. Sendo que 41,8\% dos usuários esperavam chegar em casa para realizar a refeição antes da implantação do Restaurante Bom Prato, provavelmente devido a um maior custo das refeições disponíveis no 
centro do município de Campinas. Após a implantação do restaurante, obter uma refeição adequada para essa parte da população ficou mais fácil, tanto que $68,2 \%$ dos usuários referem almoçar nesse estabelecimento pelo preço barato. Esses resultados são compatíveis com a pesquisa realizada pelo IBOPE, onde $78 \%$ dos entrevistados referem que o baixo preço influencia na escolha de realizar a refeição nos Restaurantes Populares.

\section{CONCLUSÃO}

Concluiu-se que o Restaurante Bom Prato é importante para a Segurança Alimentar e Nutricional de seus usuários, pois proporcionou à amostra, uma maior variedade de grupos de alimentos no almoço comparada ao jantar em casa e também comparada ao tipo de refeição realizada pelos pesquisados antes de sua inauguração.

Salienta-se a importância do conhecimento do perfil de usuário e suas necessidades para o planejamento do cardápio, da instalação e funcionamento de unidades com essas características. O Bom Prato de Campinas é frequentado em maior proporção por homens, usuários de ônibus, que não completaram o primeiro grau (1 $\underline{a}$ a $4 \underline{a}$ séries do ensino fundamental), desempregados, moradores do município com residência fixa.

O Restaurante Bom Prato no município de Campinas proporciona, para alguns, a única opção de realizar pelo menos uma refeição completa ao dia e em horário adequado. Também é uma maneira de se alimentar de forma saudável a baixo custo.

\section{REFERÊNCIAS}

[1] Uchimura KY, Bosi MLM. Programas de comercialização de alimentos: uma análise das modalidades de intervenção em interface com a cidadania. Rev Nutr. 2003;16(4):387-397.

[2] Cerri C, Santos AC. Fome: história de uma cicatriz social. Brasilia: 2002 [acesso em 12 set. 2008]. Disponível em: http://www.presidencia.gov.br/mesa/nt/a 09.htm

[3] Silva RR. Principais políticas de combate à fome implementadas no Brasil. Textos \& Contextos. 2006;5(1).

[4] Cohn A. Políticas sociais e pobreza no Brasil. In: Planejamento e Políticas Públicas, IPEA, número 12, jun./dez. 1995. p. 1-18.

[5] Peliano AM. O mapa da fome: informações sobre a indigência por Municípios da Federação. Documento de Política no 15, Brasília: IPEA, 1993.
[6] Brasil. Ministério Extraordinário de Segurança Alimentar e Combate à Fome. Secretaria de Programas de Segurança: Ações Integradas de Segurança Alimentar e Nutricional. Brasilia, 2003 [acesso em 05 mar 2008]. Disponível em: http://www.ptri.org.br/docs/docs $\% 20$ fome $\% 20$ zero/Doctr abalho programasfomezero.doc

[7] Burlandy L. Comunidade Solidária: engenharia institucional, focalização e parcerias no combate à fome, à pobreza e à desnutrição [tese]. Rio de Janeiro: Escola Nacional de Saúde Pública (ENSP), Fundação Oswaldo Cruz, 2003.

[8] Dalt S, Gouvêa VHC. A Questão da Segurança Alimentar e Nutricional frente ao Combate à Fome e à Pobreza no Brasil. Campinas, 2006 [acesso em 13 mar 2008]. Disponível em:

http://www.abep.nepo.unicamp.br/encontro2006/docspdf/ ABEP2006 666.pdf

[9] Instituto Cidadania. Projeto Fome Zero. Uma Proposta de Política de Segurança Alimentar para o Brasil. Versão 3, São Paulo, 2001 [acesso em 03 mar 2008]. Disponível em: http://www.fomezero.gov.br/download/livro projeto $\% 20 \mathrm{f}$ ome.pdf

[10] São Paulo. Secretaria de Agricultura e Abastecimento. Projeto de Restaurantes Populares Bom Prato. Decreto no 45.547, de 26 de Dezembro de 2000 [acesso em 08 mar 2008]. Disponível em: http://www.codeagro.sp.gov.br/bom prato/bom prato.ph $\mathrm{p}$

[11] Brasil. Portal do Governo Federal. Fome Zero, 2006 [acesso em 01 set 2008]. Disponível em: http://www.fomezero.gov.br

[12] Instituto Polis. Mapeamento e Caracterização de Restaurantes Populares, 2005 [acesso em 13 mar 2008]. Disponível em: http://www.polis.org.br/download/174.pdf

[13] Costa D. Experiência Brasileira em restaurantes populares. Bol Oficina Sanit Panam. 1947;26(5):415-21.

[14] Instituto Brasileiro de Geografia e Estatística. Síntese de Indicadores Sociais 2003. Estudos e Pesquisas. Informação Demográfica e Socioeconômica, número 12. Rio de Janeiro; 2004.

[15] Secretaria de Habitação da Prefeitura Municipal de Campinas e Companhia e Habitação Popular de Campinas Cohab. Campinas: Relatório técnico; 2003.

[16] Brasil. Ministério do Desenvolvimento Social e Combate à Fome/ASCOM. Pesquisa revela perfil de usuários de restaurantes populares, 2005 [acesso em 08 abr 2008]. Disponível em: http://www.ibope.com.br/opinião publica/downloads/opp restaurantes populares set $05 . \mathrm{pdf}$ 
Perfil do usuário de restaurante popular. Gobato et al.

[17] Philippi ST. Nutrição e Técnica Dietética. 2a ed. São Paulo: Manole; 2006.

[18] World Health Organization. Global Strategy on Diet, Physical Activity and Health, 2002 [cited 2009 jan 20]. Available:

http://www.who.int/dietphysicalactivity/strategy/eb11344/ strategy english web.pdf
[19] Maluf RS. Análise dos resultados da pesquisa Mapeamento e caracterização de restaurantes populares Instituto Polis 2005 [acesso em 13 mar 2008]. Disponível em: http://www.polis.org.br/download/170.pdf

[20] Araújo FALV, Almeida MI, Bastos VC. Aspectos alimentares e nutricionais dos usuários do "restaurante popular Mesa do Povo”. Saude Soc. 2007;16(1):117-133. 